\title{
50 anos de evolução nos estudos linguísticos transculturais: da Retórica Contrastiva à Retórica Intercultural
}

\section{David Sánchez-Jiménez}

New York City College of Technology, Estados Unidos

\author{
@dsanchezjimenez@citytech.cuny.edu_ (D) orcid.org/0000-0003-4764-0470 \\ Tradução: \\ Mirélia Ramos Bastos Marcelino \\ Cristiano Costa Magalhães \\ Eduardo Lopes Piris \\ Universidade Estadual de Santa Cruz
}

Resumo: Este trabalho apresenta um panorama histórico dos estudos linguísticos transculturais, discorrendo sobre o surgimento da retórica contrastiva por meio do trabalho seminal de Robert Kaplan em 1966 e as contribuições de Ulla Connor ao rebatizar tais estudos como retórica intercultural. Explana-se também sobre as críticas endereçadas à retórica contrastiva feitas durante os anos 1980, 1990 e 2000 e de que maneira tais críticas redefiniram o quadro teórico-metodológico e o objeto de estudo da disciplina. Conclui-se com exposição de uma crítica à homogeneização das distintas culturas retóricas causada pela globalização e internacionalização do inglês no âmbito acadêmico e nas atividades profissionais.

Palavras-chave: Retórica Contrastiva. Retórica Intercultural. Translinguismo. Transculturalidade. Multiletramentos.

\begin{abstract}
This work presents a historical overview of transcultural linguistic studies, discussing the emergence of contrasting rhetoric through the seminal work of Robert Kaplan in 1966 and the contributions of Ulla Connor in renaming such studies as intercultural rhetoric. It also explains about the criticisms addressed to the contrastive rhetoric made during the 1980s, 1990s, and 2000 s and how these criticisms redefined the theoretical-methodological framework and the object of study of the discipline. It concludes with an exposition of a critique to the homogenization of the different rhetorical cultures caused by the globalization and internationalization of English in the academic sphere and in professional activities.
\end{abstract}

Keywords: Contrastive Rhetoric. Intercultural Rhetoric. Translinguism. Transculturality. Multiliteracies. 


\section{Introdução}

A Retórica Contrastiva ${ }^{1}$ nasceu como disciplina nos anos 1960 e em sua primeira fase foi encarregada de examinar as diferenças de escrita entre distintas culturas e explorar as dificuldades - em suas origens, do ponto de vista linguístico - que esse fato gera para quem escreve em uma segunda língua, observando assim que a linguagem e a escrita são fenômenos culturais. No entanto, a escrita é uma técnica criada por convenção pelo ser humano, a partir da qual se entende que diferentes culturas têm diferentes padrões retóricos e que diferentes recursos linguísticos, textuais e discursivos sejam utilizados no momento de compor um texto (CONNOR, 1996, p. 5).

Segundo a teoria da Retórica Contrastiva, as convenções culturais são transferidas da L1 para a escrita em L2, causando principalmente interferências no nível discursivo na organização dos textos, as quais, muitas vezes, são penalizadas pelos professores nas aulas de idiomas, porque normalmente são tratadas como desvios da norma, por conferir à escrita um tom não estruturado e ilógico. A Retórica Contrastiva ajuda a entender as causas desses desvios e, uma vez examinadas, prepara o escritor para entender quais são as expectativas do leitor em relação à língua estrangeira que está aprendendo e para agir por escrito com base nessa perspectiva (LEKI, 1991, p. 137).

A partir da década de 1980, gerou-se uma discussão nessa disciplina que resultou na revisão de seus princípios teóricos e, consequentemente, numa forte e renovadora expansão das temáticas abordadas, dos objetos de estudo selecionados e da metodologia utilizada. Como resultado dessa expansão, a Retórica Contrastiva entra em contato com disciplinas como a Sociologia, a Antropologia e a Psicologia. Outro marco importante na consolidação dessa disciplina é a redefinição do conceito de cultura, cuja discussão começa no final dos anos 1990, bem como a consideração de práticas sociais que incluem o estudo do processo de composição do texto e do contexto (CONNOR, 2008,

\footnotetext{
${ }^{1}$ O presente trabalho focaliza a Retórica Contrastiva, perspectiva norte-americana que considera as diferenças culturais na retórica dos textos escritos, ignorando em nosso estudo outras abordagens nesse campo, como as da escola alemã ou francesa. É por isso que neste texto usamos, como exemplos, materiais de pesquisas que exploraram as diferenças retóricas na escrita entre a língua inglesa e a língua espanhola. No entanto, o objetivo deste trabalho é apenas indicativo e tenta exemplificar as decisões tomadas nos diferentes estágios evolutivos da Retórica Contrastiva e como esse fato impactou no desenvolvimento de um novo tema e metodologia utilizada nesta disciplina.
} 
p. 299). Nos últimos anos, uma das vias de estudo para a qual a Retórica Contrastiva tem oferecido aportes relativos aos modelos preferidos de escrita está nos textos profissionais elaborados para fins específicos, nos quais se busca garantir a eficácia da finalidade, sem que a estrutura retórico-discursiva do texto condicione a mensagem (CONNOR, 2001, p. 27; 2002, p. 493).

\section{A primeira etapa da Retórica Contrastiva: origens}

A Retórica Contrastiva emerge na Linguística Aplicada a partir dos estudos transculturais que Kaplan desenvolveu nos anos 1960. No início, essa disciplina manifesta uma clara vontade pedagógica em resposta à crescente demanda dos estudantes não nativos que se matricularam nas universidades norte-americanas durante esses anos. Kaplan (1966) nota as diferenças que ocorrem na escrita ao analisar os textos produzidos por estudantes angloamericanos, em contraste com aqueles escritos em inglês como L2 por estudantes não nativos, os quais por sua vez apresentavam coincidências entre si. Kaplan e seus colegas norte-americanos encarregados do ensino de L2, perceberam que existiam semelhanças nos padrões linguísticos e na organização retórica dos textos produzidos pelos alunos falantes de diferentes línguas maternas e que, por isso, era fácil estabelecer uma taxionomia desses desvios e identificar a origem dos indivíduos que os cometiam, como atesta Kaplan (1988, p. 277):

Os professores de inglês com experiência em L2 afirmaram, com incrível precisão, qual era a língua materna de cada escritor, simplesmente lendo os textos produzidos por esses escritores (independentemente, é claro, das pistas fornecidas no texto, por exemplo, o nome da cidade, de uma pessoa famosa). Essa evidência sugere que devem haver regularidades na escrita em inglês de alunos não nativos, as quais têm origem em sua língua materna específica e que podem ser observadas e codificadas, para desenvolver conteúdos e estratégias para o ensino de cursos de inglês como L2. Isso também implicou que havia regularidades no inglês escrito de falantes nativos de inglês e que havia regularidades nas diferenças entre a escrita dos falantes nativos e dos não nativos (KAPLAN, 1988, p. 277).

O contexto teórico no qual se enquadra o estudo fundador de Kaplan (1966) é descrito por Matsuda (1977), que alude às três diferentes tradições intelectuais, muito em voga na época, como base teórica subjacente sobre a qual se assenta sua discussão: a análise contrastiva aplicada no ensino de 
línguas neste período; a hipótese da relatividade linguística de Sapir e Whorf; a retórica geradora do parágrafo, de Christensen (1963).

No que diz respeito à análise contrastiva, foram inicialmente seguidos os princípios propostos pelos linguistas Fries e Lado, que consideravam que os erros podiam ser previstos e corrigidos mediante o contraste de línguas. Kaplan pretendia fazer o mesmo na escrita de textos e apontou que a interferência de L1 em L2 era o principal obstáculo que o aluno de uma língua estrangeira encontrava na aquisição da língua-alvo. No entanto, em vez de se limitar à análise sintática, o estudo de Kaplan (1966) desenvolveu essa teoria a fim de comparar as estruturas do discurso por meio das diferentes culturas envolvidas no estudo.

Por outro lado, a hipótese de Sapir-Whorf da relatividade linguística sugere que diferentes línguas afetam a percepção e o pensamento de maneiras distintas. Whorf, um discípulo de Sapir, elabora uma teoria linguística baseada em suas ideias: as formas de pensamento dos seres humanos são controladas pelas leis dos modelos do que é inconsciente. A partir deste princípio, entende-se que cada língua é um sistema-modelo diferente dos outros e tem a capacidade de controlar o pensamento, ou seja, que a linguagem humana exerce uma influência primária sobre o pensamento (CONNOR, 1996). Vez Jeremías (2002) interpreta essa teoria com as seguintes palavras:

\footnotetext{
A linguagem não é um instrumento de registro passivo dos acontecimentos que reflete uma realidade preexistente. Muito pelo contrário, nossas línguas forjam nossa concepção do que é a realidade e como a percebemos. O que essa realidade é para qualquer um de nós se torna uma função da língua em que a expressamos (VEZ JEREMIAS, 2002, p. 6).
}

Segundo Trujillo Sáez (2001), a hipótese do relativismo linguístico de Whorf distingue uma versão fraca, em que se revela a influência que a língua exerce sobre o pensamento, de uma versão forte, na qual se sustenta que a linguagem humana controla o pensamento e a percepção. A primeira será aquela que terá melhor recepção dentro da Retórica Contrastiva e a segunda será descartada devido à rigidez de suas premissas. Steven Pinker (1994), nesse sentido, argumenta a partir de uma concepção chomskyana que não é possível provar cientificamente essa hipótese e, consequentemente, deve ser 
considerada apenas como uma hipótese sobre o desempenho da linguagem, mas não sobre a própria competência.

Com base nos trabalhos de Christensen (1963) sobre retórica gerativa do parágrafo, as investigações de Kaplan (1966; 1988) representam um avanço significativo na análise dos textos, o que implicou a abertura de novos caminhos para a Linguística Textual, uma vez que a unidade de análise da frase, tal como Bloomfield (1933) havia proposto, foi ampliada para a do parágrafo no campo da gramática. Essa proposta mostrou uma tentativa incipiente de dotar a disciplina de um método de análise que ultrapassasse o âmbito frasal e daí seu esforço em substituir a unidade de análise do discurso da frase pela do parágrafo.

Como comenta Pastor Villalba (2005, p. 16), essa visão revolucionária de Kaplan (1966) superou o modelo anterior, porque transcendeu a análise retórica e linguística estática do texto, com o objetivo de estabelecer a relação dinâmica entre as frases que compunham o parágrafo. Com isso, Kaplan estava à frente de seu tempo ao propor o parágrafo como unidade de análise, tornando-se assim o primeiro autor a realizar uma investigação utilizando este procedimento, mesmo quando não dispunha dos instrumentos metodológicos necessários para tal. Por esse motivo, Connor (1996) justifica que este primeiro estudo acabou sendo um trabalho mais intuitivo que científico, protegendo o autor das críticas que recebeu como resultado das conclusões dessa investigação.

Portanto, Kaplan (1966) inaugura os estudos de Retórica Contrastiva, oferecendo um novo desenvolvimento metodológico nunca antes visto na análise textual a partir de um estudo em que ele analisou 598 ensaios escritos em inglês por alunos de diferentes L1. A hipótese de sua pesquisa afirmava que as estruturas retóricas utilizadas pelos estudantes não nativos que escrevem em inglês têm como base a lógica interna de sua língua materna, que obviamente não é comum a todos os estudantes e que varia de uma cultura para outra, questão que o pesquisador resume da seguinte maneira:

A Lógica (além do sentido popular do termo), que é a base da Retórica, evolui com a cultura, não é universal. A Retórica, portanto, também não é universal, mas varia de cultura para cultura e de tempos em tempos dentro da mesma cultura (KAPLAN, 1966, p. 2). 
Nessa análise das diferenças culturais, Kaplan (1966) distinguiu cinco tipos de desenvolvimento no parágrafo em função da língua de origem, cujo esquema foi sintetizado em cinco diagramas interpretativos correspondentes:

Figura 1 - Diagrama das diferenças transculturais na organização do parágrafo

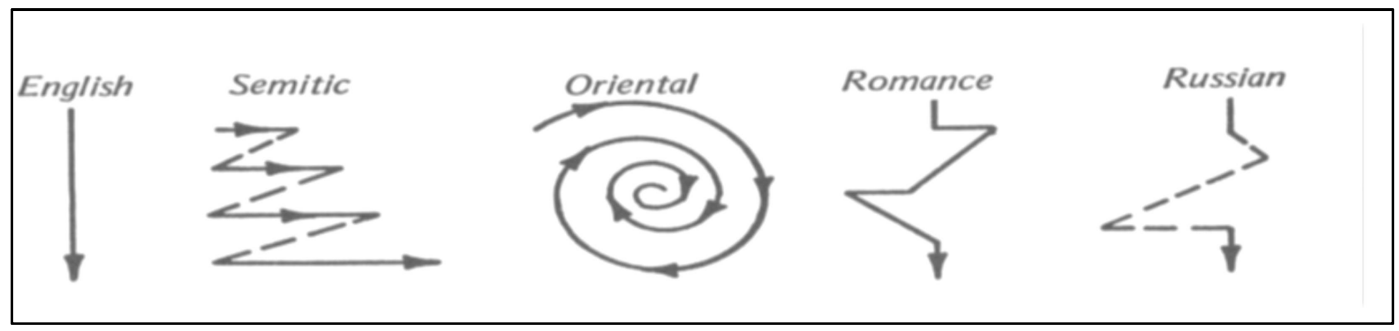

Fonte: Kaplan (1966, p. 15)

Como discutido ao longo desta seção, a pesquisa de Kaplan (1966) foi a primeira a propor a teoria de que a escrita é influenciada pela cultura, inaugurando, assim, estudos sobre composição em L2 (CONNOR, 1996; KROLL, 2003; MATSUDA 2003). Os resultados mostraram que os textos expositivos escritos em inglês como L1 se desenvolviam de maneira linear, enquanto que os escritos em inglês como L2 por nativos das línguas românicas e do russo apresentavam clara tendência à digressão e à inclusão de materiais estranhos ao tema, resultando em subordinação irrelevante, às vezes, com relação à ideia central desenvolvida no texto. Isso implica que existe, para os escritores de textos românicos e russos, maior liberdade para introduzirem materiais que os escritores de outros grupos considerariam estranhos, uma vez que neles o discurso é caracterizado pela digressão do tema central. Em relação aos textos orientais, concluiu-se que são indiretos por postergar a ideia temática para o final do parágrafo, enquanto as línguas semíticas se caracterizam pelo uso de orações coordenadas paralelas.

Este e outros sucessivos trabalhos de Kaplan (1966; 1978; 1983; 1987; 1988) ao longo dos anos 1970 e 1980, bem como as contribuições dos seguidores de seu modelo, insistem na necessidade de aplicar a análise textual dos parágrafos com o objetivo de definir as diferenças entre os padrões retóricos e sintáticos que podem aparecer na escrita das diferentes línguas. Embora algumas críticas posteriores (HINDS, 1983; 1987; 1990; LEKI, 1991; 
LIEBMAN, 1992; MATSUDA, 1997; KUBOTA, 1998; TRUJILLO SÁEZ, 2004²) tenham tentado diminuir a representatividade e a veracidade científica dos resultados do estudo de 1966 em relação à abordagem teórica e ao desenho da pesquisa, a verdade é que as intuições teóricas enunciadas por Kaplan em 1966 têm chegado até os dias de hoje - como veremos na seção seguinte enriquecidas por uma evolução que teve continuidade na definição do objeto de estudo e na metodologia da Retórica Contrastiva.

Tais críticas e revisões permitiram a essa teoria interagir com outras disciplinas e desenvolver nesse campo pesquisas mais concretas sobre temas específicos da escrita a partir das perspectivas etnográfica, social e cognitiva. Apesar das críticas que, com o passar do tempo, foram chegando de diversos setores e escolas disciplinares, o que é inegável, como reconhecem Connor (1996) e Trujillo Sáez (2004) entre outros autores, é que, apesar das carências técnicas e metodológicas próprias do momento em que foi realizado o estudo, foi Kaplan que começou a pesquisa no campo da escrita em L2, ao mesmo tempo que propiciou o desenvolvimento da descrição e da avaliação de textos escritos, bem como o levantamento de múltiplas hipóteses sobre padrões de escrita em várias línguas e culturas. No entanto, com este artigo de 1966, Kaplan estabeleceu o método de pesquisa que viria a predominar na primeira década da vida de Retórica Contrastiva, baseado na análise textual do parágrafo. Entre outros estudos que dão continuidade ao trabalho de Kaplan dentro da análise textual, vale destacar os assinados por Santiago (1970, apud MONTAÑO-HARMÓN, 1991) e Santana-Seda (1974). E, em 1987, é publicado o primeiro trabalho de estudos empíricos e análise de texto em Retórica Contrastiva, Writing across languages: Analysis of L2 text, organizado por Connor e Kaplan, contribuindo para o estabelecimento desse campo de estudo.

No contexto de uma revisão historicista dos estudos de escrita em L2, Matsuda (2003, p. 20) aponta que a Retórica Contrastiva foi a primeira tentativa da Linguística Aplicada que surgiu com o objetivo de explicar de que maneira se produzia a escrita em L2. A ampliação de estudos no campo da Retórica Contrastiva responde, em parte, à necessidade de compreender os

\footnotetext{
${ }^{2}$ Trujillo Sáez (2004) sintetiza e desculpa essas críticas ao comentar que se tratava de um método de pesquisa-ação mal elaborado, fruto da curiosidade e da necessidade apressada de encontrar respostas, aplicando uma finalidade pedagógica concreta para solucionar um novo problema didático que surgiu nos anos cinquenta.
} 
desvios encontrados nas composições do crescente número de estudantes estrangeiros nas universidades estadunidenses ${ }^{3}$, como observado anteriormente, devido principalmente às convenções linguísticas e retóricas da L1 que interferiam na escrita em L2. Sobre esse período inicial, Connor (2008, p. 300-301) comenta como a Retórica Contrastiva teve de abrir caminho em um terreno hostil onde havia apenas teorias e materiais disponíveis para o ensino. Portanto, os fundamentos dessa disciplina foram estabelecidos em terrenos baldios e os primeiros teóricos tiveram de abrir caminho intuitivamente, o que gerou um grande número de críticas ao longo de seu desenvolvimento:

Em primeiro lugar, poucos professores de Inglês para Fins Específicos refletiram o suficiente sobre a escrita. A metodologia principal - o Método Audiolingual se concentra nas competências orais. Em segundo lugar, a principal preocupação tanto da linguística quanto do ensino de línguas estava no nível "frasal" em vez do nível discursivo. Terceiro, as pessoas não consideravam que a escrita poderia ser ensinada. Era apenas uma questão de você nascer com um dom para escrever ou não. Os programas de retórica e redação começaram, então, a ser incorporados ao currículo das universidades dos Estados Unidos (CONNOR, 2008, p. 300-301).

No entanto, a aplicação desses conhecimentos dava resposta a um problema concreto e, por esse motivo, obteve boa repercussão entre professores e pesquisadores, que acolheram essa teoria inovadora com bons olhos. Posteriormente, os estudos nesse campo se fortaleceram até se tornarem uma das principais correntes de pesquisa em segunda língua, incorporando novos recursos e técnicas metodológicas de outras disciplinas.

\section{Críticas ao primeiro modelo de Retórica Contrastiva}

Se desde as décadas de 1970 a 1980 a linha estabelecida por Kaplan $(1966 ; 1978 ; 1983 ; 1987 ; 1988)$ foi seguida nesses primeiros estudos de Retórica Contrastiva, no final da década de 1980, começam a surgir pesquisas desconectadas dos princípios metodológicos estabelecidos por esse investigador. Hinds (1983; 1987; 1990) é um dos nomes dessa nova geração, que trouxe um novo ar à Retórica Contrastiva a partir do impulso dado à renovação da metodologia de investigações transculturais e também por seus trabalhos críticos anteriormente realizados nessa disciplina. Em relação à

\footnotetext{
${ }^{3}$ Dados detalhados podem ser encontrados em Kroll (2003) e Matsuda (2003).
} 
metodologia, Hinds (1983; 1987; 1990) alerta para a necessidade de não se limitar à análise textual nas investigações de Retórica Contrastiva e se preocupar com a relevância da recepção dos textos e as expectativas da audiência, introduzindo assim o conceito de distribuição de responsabilidade entre o escritor e o leitor na composição do texto. Para realizar esta renovação, Hinds (1983; 1987; 1990) revisa as teses de Kaplan (1966) e a metodologia utilizada em sua pesquisa, com o objetivo de se concentrar fundamentalmente na interpretação que o leitor faz do texto e nas características de sua recepção. Em outras palavras, a preocupação de Kaplan (1966; 1988) em identificar as diferenças organizacionais nos textos escritos por falantes não nativos fica relegada a segundo plano, uma vez que Hinds (1983; 1987; 1990) volta seus estudos para o impacto que as diferenças culturais têm sobre o leitor nas comunidades que recebem e interpretam o texto.

Assim, por exemplo, na análise da linguagem expositiva japonesa, Hinds descobre que o compromisso por parte do leitor com o texto difere da função que adota em outras culturas. Partindo dessa premissa, ele deduz em seu estudo que os leitores ingleses esperam que o autor desenvolva textos claros, diretos e bem coesos em um modo dedutivo, enquanto os leitores japoneses, ao contrário, realizam um trabalho interpretativo para preencher as carências organizacionais que apresenta o texto mais fortemente carregado de um componente indutivo. Em outras palavras, o grau de responsabilidade que o leitor, em diferentes culturas, tem na interpretação da escrita varia diferentemente, assim como varia o esforço que o escritor deve fazer para tornar o texto coerente por meio de transições e do uso de metatextos (CONNOR, 2002, p. 496). Nesse sentido, o relato de Matalene (1985) com estudantes chineses concorda com essas observações sobre a maior indiretividade 4 do texto produzido pelo emissor e o maior esforço interpretativo a ser feito pelo receptor, se comparado à perspectiva ocidental. Esse novo olhar sobre a composição dos textos permite reinterpretar o

\footnotetext{
${ }^{4}$ N.T.: Sobre a categoria diretividade/indiretividade, ver o artigo de Deborah Tannen "Indirectness in discourse: Ethnicity as conversational style" (1981) e os livros Politeness: Some Universals in Language Usage, publicado em 1987 por Penelope Brown e Stephen Levinson, Cross-cultural pragmatics: the semantics of human interaction, de Anna Wierzbicka publicado em 1991. Em espanhol, indicamos o artigo de Georgina Analía Lacanna "No des más vueltas. Un estudio del uso de la indireccionalidad en la realización de invitaciones y propuestas en interacciones por WhatsApp", publicado na revista brasileira Calidoscópio, em 2018.
} 
desenho metodológico da pesquisa em Retórica Contrastiva e, assim, evitar a rigidez característica do modelo que dominou os primeiros anos dessa disciplina.

Por outro lado, Hinds (1983, p. 186), referindo-se explicitamente ao modelo de Kaplan (1966), ressalta que ele estudou unicamente a produção em L2 de estudantes não nativos, podendo ser que os erros cometidos por estes tenham ocorrido devido à interlíngua dos estudantes ou a outros fatores que podem não estar diretamente relacionados aos usos retóricos e as convenções culturais próprias da L1 do escritor. Para Hinds (1983, p. 186), portanto, é essencial estudar tanto as produções dos alunos em sua L1 quanto as de sua L2 - como fez Santana-Seda (1974) pela primeira vez -, para considerar quais são as características específicas nas quais há interferência, isso sempre após ter analisado o comportamento do aluno em sua língua materna.

Como consequência dessa nova perspectiva, não era possível determinar se os erros produzidos no texto da língua que o aluno está aprendendo foram causados em sua origem por diferenças retóricas com a L1 ou, simplesmente, pela inexperiência, o desconhecimento dos gêneros textuais na sua L1 e a falta de treinamento do estudante na composição de textos escritos. É o caso, por exemplo, do estudo de Mohan e Lo (1985) com estudantes chineses. Esses pesquisadores alertam que os erros cometidos na escrita por esses informantes não se deviam tanto às diferenças culturais das convenções escritas como às dificuldades implícitas que encontraram devido à sua condição de escritores inexperientes.

Para Hinds (1983), uma segunda crítica ao modelo proposto por Kaplan (1966) enfatizou o uso dos termos genéricos que englobavam diferentes línguas, como o de línguas orientais para se referir a escritos resultantes de nacionalidades, línguas e culturas tão diferentes como a coreana, a chinesa ou a tailandesa. Entendeu-se aí que a ênfase colocada nessas diferenças tipificava e contribuía para a criação de estereótipos sobre as línguas.

Em terceiro lugar, o etnocentrismo subjacente à pesquisa de Kaplan (1966) tem sido um dos alvos preferidos dos críticos desse modelo (LEKI, 1991; RAIMES, 1991; SPACK, 1997; ZAMEL, 1997; KUBOTA, 1998; 1999; KUBOTA; LEHNER, 2004), em que o inglês foi imposto como norma e padrão a seguir devido à sua diretividade e por ser a língua direta e coerente, em comparação 
com as outras línguas tidas como incoerentes e digressivas. Como lembra Leki (1991), para fazer esse tipo de generalização sobre o estilo do inglês, tanto Kaplan quanto os outros pesquisadores se basearam nas descrições da língua inglesa que figuravam nos manuais de estilo da década de 1960, as quais ignoravam completamente outras variações do inglês não normativo. No desenho das investigações, esse etnocentrismo se traduz na assunção de uma perspectiva ocidentalizada, ao estabelecer os objetivos e delimitar os instrumentos de pesquisa, seus procedimentos de análise e de interpretação dos dados. Por essa razão, Connor (1996) propõe que um esforço maior seja feito para entender os fatos observados a partir da lógica do outro, fornecendo assim algumas diretrizes necessárias para evitar esse etnocentrismo no planejamento de um estudo de Retórica Contrastiva, tal como a necessidade de trabalhar em conjunto com pesquisadores de nacionalidades das línguas em estudo.

A esses comentários e análises críticas de Hinds (1983; 1987; 1990) sobre Retórica Contrastiva nas décadas de 1960 e 1970, muitos outros foram adicionados durante as décadas seguintes (MATALENE, 1985; LEKI, 1991; RAIMES, 1991; MATSUDA, 1997; SCOLLON, 1997; SPACK, 1997; ZAMEL, 1997; KUBOTA, 1998; 1999; (ANAGARAJAH, 2002; KUBOTA; LEHNER, 2004), como aqueles que apontam a dificuldade de a Retórica Contrastiva em responder com abordagens didáticas às diferenças culturais que se manifestam na produção de textos (CONNOR, 2002; 2008). Essa crítica alude ao fato de que a pesquisa em Retórica Contrastiva até então se concentrou no produto escrito, sem prestar tanta atenção à maneira como o texto havia sido composto ou aos processos percorridos pelos alunos e suas estratégias de elaboração. Longe dessa perspectiva, o texto era examinado apenas de um ponto de vista estático e considerado como um resultado final, como um produto (LEKI, 1991, p. 123):

Os defensores do enfoque baseado no processo sustentam que a pesquisa em Retórica Contrastiva examina apenas o produto, separando-o do processo pelo qual os escritores tiveram de passar para chegar à produção do texto (LEKI, 1991, p. 123).

Nesse sentido, Leki (1991) indica uma nova direção sobre a qual a Retórica Contrastiva deve colocar sua atenção, concentrando-se no estilo de escrita do aluno em sua L1 e seus efeitos na aprendizagem de uma nova 
língua. Para isso, a autora alerta que os teóricos e pesquisadores de Retórica Contrastiva devem ecoar os estudos sociológicos realizados em Educação e Letramento ${ }^{5}$, como é o caso do projeto da International Association for the Evaluation of Educational Achievement [Associação Internacional para a Avaliação do Rendimento Educacional] (IEA), promovido por Purves (1988), que atende às convenções da escrita que se desenvolvem na educação escolar da criança.

Liebman (1992), por outro lado, reivindica a expansão do objeto de estudo, uma vez que, nas primeiras investigações da Retórica Contrastiva, o conceito de retórica se reduzia a um único aspecto, a dispositio, o planejamento ou a organização do texto, em vista das cinco partes que compõem a retórica tradicional: inventio, dispositio, elocutio, memoria, actio. Por sua vez, Matsuda (1997) chama esse primeiro modelo da Retórica Contrastiva de determinista, aludindo ao fato de que a aplicação didática proposta nas aulas de redação parece estar programada para os escritores elaborarem seus textos de uma determinada maneira. Trata-se de fugir, em sala de aula, de todos os traços de influência da L1, sendo a tarefa prioritária do professor reiniciar o aluno em uma visão limitada que ignora outros aspectos da escrita tão ou mais relevantes do que a transferência de convenções retóricas. Nesse sentido, outros autores, como Kubota (1998), criticaram Kaplan por não ter considerado os benefícios da transferência da L1 para a L2, concentrando-se apenas na consideração negativa dessa estratégia de aprendizagem.

Embora o objetivo deste artigo não seja realizar uma revisão exaustiva de todos os argumentos críticos e as consequentes respostas geradas a esse respeito, mas sim dar um testemunho dessa situação, seria injusto não fazer menção à reflexão que essa controvérsia promoveu dentro da Retórica Contrastiva. No entanto, os continuadores dessa disciplina sempre foram receptivos a essas críticas e seguiram trabalhando com o objetivo de corrigir os erros do passado e poder avançar com passo firme. Assim, por exemplo, Grabe e Kaplan (1996, p. 186) reconhecem que um dos maiores problemas que

\footnotetext{
${ }^{5}$ Uma visão mais atualizada da aplicação da Retórica Contrastiva na sala de aula, que inclui as últimas tendências metodológicas e temáticas exploradas pela Retórica Intercultural, pode ser encontrada em Connor (2011), obra que surgiu com a intenção de responder às críticas que, durante décadas, questionaram a competência da Retórica Contrastiva em fornecer uma pedagogia válida para seus princípios teóricos e incursões empíricas no campo da interculturalidade.
} 
a Retórica Contrastiva teve de enfrentar foi controlar as variáveis que intervêm nas pesquisas, que nem sempre foram bem-sucedidas. Por isso, eles propõem desenvolver novas metodologias de estudo mais modernas e criativas, mas também afirmam que estão sendo feitos progressos consideráveis nessa direção e que as ferramentas de estudo estão se tornando cada vez mais valiosas.

Um ano depois, Ramanathan e Kaplan (1997) responderam positivamente às críticas de Raimes (1991) e Zamel (1997) sobre as possibilidades de aplicação da Retórica Contrastiva na sala de aula. Nesse sentido, o próprio Kaplan (2000: VII) comenta anos depois, assumindo alguma responsabilidade, esse assunto: “embora a Retórica Contrastiva exista há 35 anos nos Estados Unidos (KAPLAN, 1966), ela praticamente não teve impacto na visão tradicional da aula de composição nos Estados Unidos". Sobre essa mesma questão, Panetta (2000, p. 7-8) declara que:

[...] os instrutores podem incorporar a retórica contrastiva nas estratégias que usam em suas aulas. $O$ que deve ser adicionado a essas estratégias é simplesmente uma base na retórica contrastiva, e isso pode ser conseguido fazendo convenções ocidentais explícitas por escrito.

Por sua vez, Connor (1996; 2001; 2002; 2004; 2008; 2011) sempre defendeu os avanços teóricos e metodológicos na Retórica Contrastiva por meio da expansão interdisciplinar que os promove, contrariamente àqueles que acusam essa disciplina de imóvel, alegando que ela permaneceu ancorada na análise linguística dos textos. Assim, em suas publicações recentes, Connor (2004; 2011) apontou avanços metodológicos nesse campo e sua aplicação efetiva na sala de aula. Em relação às críticas feitas à visão etnocêntrica da língua inglesa que predominou nas primeiras investigações em Retórica Contrastiva, Connor (1996) já recomendava a necessidade de pesquisas conjuntas com pesquisadores falantes nativos das línguas envolvidas no estudo. Em 2008, Connor comenta como o conceito de "Small Cultures", cunhado por Holliday (1994; 1999), contribuiu para diminuir a dependência do uso de termos definidores de nacionalidade e concentrar a atenção na comparação de grupos sociais concretos.

Em conclusão, todas essas críticas discutidas ao longo desta seção têm como consequência que, nos anos 1980, é realizada uma revisão completa dos princípios fundamentais que sustentam essa disciplina. Nesses anos, a 
disciplina se reinventa com a escolha de objetos de estudo ainda não explorados na Retórica Contrastiva e com uma perspectiva metodológica que define o principal objetivo de expandir as visões dessa ainda jovem disciplina.

\section{Segunda etapa da Retórica Contrastiva: especialização}

Trujillo Sáez (2004) reflete acerca das deficiências metodológicas na pesquisa em Retórica Contrastiva na década de 1980, em sua primeira etapa, e detecta como o mais notável é a sinergia de teorias e métodos que cada autor utiliza para desenvolver sua pesquisa, fato que dificulta a comparação dos resultados das diferentes investigações, já que estas se medem com parâmetros desiguais. Isso é mais evidente a partir dessa década, quando se começam a realizar pesquisa sobre Retórica Contrastiva em diferentes disciplinas. Os grandes projetos, como o International Education Achievement $(\mathrm{IEA})^{6}$, igualmente se ressentem da falta de uma concepção adequada na elaboração de testes e coleta de dados, de modo que os enunciados dos temas sobre os quais os alunos devem escrever e a maneira de realizar a tarefa são suscetíveis de diferentes interpretações a depender da cultura do aluno.

Os primeiros pesquisadores de Retórica Contrastiva atribuíram uma aplicabilidade universal à análise ocidental, o que é um erro grave. As metodologias de estudo e os parâmetros aplicados foram ocidentais, tais como a consideração da linearidade do tempo, que é diferente nas culturas orientais. Assim, por exemplo, Indrasuta (1988, p. 219) mostra que, para os estudantes tailandeses, escrever um texto narrativo não é apenas um meio de entretenimento no qual uma história é contada, mas também adquire um valor pedagógico significativo, tornando-se um instrumento didático de exibição e instrução para a comunidade receptora. Portanto, se partimos de diferentes expectativas culturais na audiência que recebe os textos, sua concepção varia. Não é novo esse argumento da variabilidade das provas durante a condução de uma pesquisa, que já havia sido questionada anos

\footnotetext{
${ }^{6}$ Purves (1988) foi o principal impulsor do International Education Achievement (IEA), um estudo que comparava a escrita de alunos do ensino médio em 14 países em sua língua materna, com a convicção de que a escrita reflete as convenções ensinadas na escola e reproduz as preferências culturais do estilo de discurso da comunidade. No entanto, Purves e Purves (1986) alertam que o estudo da IEA examina a escrita em L1 e apenas em contextos de escrita L1, uma limitação que não permite muitas generalizações sobre a aquisição de L2, embora outros defendam a validade do estudo (SÖTER, 1988).
} 
antes por Tarone (1983). Essas questões relacionadas à variabilidade nos impedem de falar sobre um modelo teórico universal para estabelecer o contraste na Retórica Contrastiva, devido às diferenças na metodologia utilizada, na nomenclatura e nas bases empíricas da investigação. Trujillo Sáez (2004, p. 67) acredita que, ao não serem comparáveis, os resultados obtidos nos estudos reduzem a validade das pesquisas e transformam a disciplina numa colcha de retalhos, na qual cada autor usa sua própria assinatura. No entanto, nos anos seguintes, será feita uma tentativa de remediar esse problema.

Com relação a esses primeiros anos, Connor (1996, p. 162) comenta que os maiores problemas na pesquisa da Retórica Contrastiva têm sido a pequena quantidade de grupos estudados, a mistura de gêneros e a generalização dos dados de L2 para L1. Destaca também o problema do etnocentrismo nas primeiras pesquisas em Retórica Contrastiva, em que o resultado de assumir que o olhar da própria cultura é central para a realidade de todo o mundo, cujas consequências mais importantes são as estereotipagens negativas das línguas e culturas dos outros. Para isso, Connor (1996) recomenda que as pesquisas trabalhem com um colaborador nativo da língua que se pretende estudar, uma vez que os colaboradores internacionais podem proporcionar uma sensibilidade cultural em cada etapa da pesquisa: "os colaboradores internacionais podem ajudar-se uns aos outros, sendo sensíveis às percepções culturais em cada estágio da pesquisa" (CONNOR, 1996, p. 163).

Esses e outros problemas menores foram sendo resolvidos ao mesmo tempo que a Retórica Contrastiva evoluiu e superou as críticas internas e externas à disciplina. Acumulando anos de experiência e tornando-se multidisciplinar, a Retórica Contrastiva dotou os estudos de um maior número de técnicas de análise e uma especificidade adequada para medir os diferentes aspectos psicológicos, sociais, antropológicos ou linguísticos envolvidos nos textos. Apesar das carências metodológicas apontadas nas seções anteriores, dessas e de outras críticas e da busca de soluções para os problemas nelas levantados, surgem, na década de 1980, um panorama renovado e uma segunda fase nos estudos de Retórica Contrastiva. Tais inquietações provocam o desenvolvimento e o aprimoramento das posições teóricas, do objeto de estudo, das ferramentas de análise usadas em estudos transculturais, dos projetos de pesquisa e, em última análise, da metodologia 
usada nas pesquisas (TRUJILLO SÁEZ, 2002, p. 55). Connor (2002, p. 495) aponta: "essas novas diretrizes implicam também visões inovadoras da cultura, do letramento e da pedagogia crítica, e têm um grande impacto na pesquisa de Retórica Contrastiva".

Sem dúvida, o principal elemento que permite esse ressurgimento da Retórica Contrastiva e que também possibilita a ampliação do seu campo de estudo, já que seu interesse linguístico primeiro era muito limitado, é a interdisciplinaridade: Linguística, Educação, Análise do Discurso, Sociolinguística e Psicolinguística intervêm de maneiras muito diferentes nas novas pesquisas em Retórica Contrastiva.

A Linguística, por exemplo, forneceu ferramentas para a análise estrutural de textos, enquanto a Educação e a Psicologia enriqueceram os métodos quantitativos experimentais e a Antropologia Social tem privilegiado métodos de pesquisa qualitativa, como estudos de caso e os etnográficos (CONNOR, 1996, p. 153). Essa extensão da metodologia utilizada na Retórica Contrastiva supera a escolha do objeto de estudo a partir da análise linguística do texto, para considerar os aspectos psicológicos, sociais e pragmáticos que afetam o discurso para além do próprio texto. $E$, como consequência desse fato, a Retórica Contrastiva evoluiu a partir da análise da superestrutura, a coesão e a coerência dos textos, para considerar novos âmbitos psicológicos e sociais permeáveis ao estudo intercultural e interdisciplinar, em consonância com os trabalhos desenvolvidos pela Análise Crítica do Discurso, como as retóricas de poder entre as diferentes comunidades (a linguagem das minorias, mulheres, imigrantes, gays entre outros) e suas manifestações nos usos retóricos, nas diferentes convenções de escrita em centros educacionais de diferentes países e nos modelos socioculturais de escrita dos vários grupos profissionais e acadêmicos. Uma ênfase especial é colocada na análise contrastiva dos gêneros, dos quais são investigadas as semelhanças e diferenças que os textos apresentam nas diferentes comunidades sociais no nível discursivo. A aplicação dessas novas teorias se materializou em duas publicações conjuntas representativas dessa nova orientação, tais como Panetta (2000) e Connor, Nagelhout e Rozycki (2008). Em conclusão, de tudo o que foi discutido nesta seção pode-se deduzir que a abordagem do texto não pode mais ser apenas linguística, pois a atividade humana e os usos 
pragmáticos e sociológicos da linguagem também devem ser considerados (CONNOR, 2002; TRUJILLO SÁEZ, 2004).

Em seus trabalhos mais recentes, Connor (2001; 2002; 2008; 2011) enunciou as quatro grandes áreas de renovação da Retórica Contrastiva em sua segunda fase, que têm sido os principais marcos na evolução da disciplina: os avanços da Linguística Textual Contrastiva; o estudo da escrita como atividade cultural na Educação; os estudos de caso da escrita em sala de aula; os estudos contrastivos de gêneros específicos. Connor (1996) aponta que nessa época a Retórica Contrastiva já havia superado totalmente sua reflexão linguística, dando maior atenção aos aspectos cognitivos e socioculturais da escrita, em articulação com os aspetoslinguísticos. Assim, os preceitos puramente linguísticos, mais interessados na análise estrutural dos produtos, são substituídos para que a pesquisa focalize as composições de L1 e em novos desenvolvimentos em Análise do Discurso e Linguística Textual, bem como nos aspectos cognitivos e sociais da escrita. Connor (1996) afirma que, como resultado do emprego dessas novas ferramentas, os textos são considerados entidades dinâmicas e seus processos ocorridos passam a ser examinados em uma grande variedade de situações de escrita.

Da Linguística Textual e da Análise do Discurso, foram adaptadas uma boa parte das ferramentas metodológicas destinadas à análise do texto, fazendo a metodologia quantitativa - que havia dominado os estudos das décadas anteriores - evoluindo para novos modelos de pesquisa adaptados ao seu objeto de estudo. Predominaram os estudos etnográficos que examinam as relações sociais que os estudantes mantêm na escrita em sala de aula, as entrevistas que cotejam os processos cognitivos utilizados na composição e as expectativas de qualidade dos textos em função dos leitores. Nessa segunda etapa, ainda que com menor presença na Retórica Contrastiva, também se tem em conta os estudos experimentais que buscam provar hipóteses (CONNOR, 1996, p. 153-165). Entretanto, em suas publicações mais recentes, Connor (2004; 2008; 2011) afirma a necessidade de um número maior e mais variado de investigações desse tipo, com o objetivo de saber como a escrita contribui para a construção social do conhecimento. Para isso, em vez de se concentrar unicamente nos textos, Connor (2004; 2008; 2011) sugere que a pesquisa deve emergir deles e, por meio de procedimentos etnográficos, encontrar respostas válidas para essas questões. 
Desde seu artigo "Intercultural rhetoric research: beyond texts", de 2004, e seus trabalhos subsequentes, Connor (2008; 2011) contempla três principais vias metodológicas de análise para a pesquisa em Retórica Intercultural, uma redefinição conceitual que engloba a Retórica Contrastiva. A autora insiste em superar as barreiras impostas pelo texto para estudar os contextos em que a escrita e o uso da linguagem na interação social ocorrem por meio de procedimentos etnográficos (observação direta, entrevistas e outras formas de análise do contexto situacional) (CONNOR, 2004, p. 294).

Por outro lado, a análise dos gêneros acadêmicos e profissionais tem sido uma das tendências mais produtivas dos últimos anos. Em princípio, os estudos focalizaram o contraste dos movimentos e passos retóricos da organização do discurso em diferentes culturas, ainda que na última década tenham se aberto ao campo da pragmática, estudando principalmente os procedimentos utilizados por diferentes culturas na transmissão da cortesia e da persuasão. Nesse campo, outra perspectiva interessante é o estudo de núcleos culturais menores, como idade, gênero, formação profissional do escritor etc. (CONNOR, 2004, p. 297). Por fim, em relação ao estudo dos gêneros, outra alternativa metodológica para sua análise é a da Linguística de Corpus. Essa técnica oferece a possibilidade de trabalhar com corpora mais amplos de textos que permitem a generalização dos resultados do estudo, o que é muito útil no meio acadêmico (AINCIBURU, 2012).

O desenvolvimento da sociedade da informação também está promovendo novos objetos de estudo, aos quais deve ser dada uma resposta por meio de uma adaptação metodológica adequada. Um desses estudos focaliza os aspectos multidimensionais do texto, considerando todos os elementos que o compõem, como gráficos, diagramas, fotografias, ícones ou formas e cores utilizadas (VENTOLA, 2007 apud CONNOR, 2008; 2011; PALTRIDGE, 2012). Por outro lado, as novas tecnologias exigem a elaboração de procedimentos metodológicos genuínos que se enquadrem na proposta de pesquisa, como no estudo de Xing, Wang e Spencer (2008), que investigaram o potencial das novas tecnologias e da aplicação do e-learning para que estudantes de línguas (chineses que estudam inglês) pudessem tomar consciência das diferenças culturais nos estilos de escrita dos falantes de ambas as línguas. 
Sem dúvida, como vem ocorrendo desde o nascimento da Retórica Contrastiva, novas formas de produção de conhecimento irão gerar novas necessidades metodológicas de análise. É por isso que a disciplina deve estar atenta a essas mudanças, a fim de oferecer uma resposta adequada que valide novas pesquisas que virão. É certo que, como já aconteceu no passado, as críticas constantes servirão de estímulo e alerta aos pesquisadores dessa disciplina, para que continuem de forma dinâmica, oferecendo respostas articuladas às necessidades metodológicas que virão.

\section{Línguas com fins específicos, gênero e Retórica Contrastiva}

$\mathrm{Na}$ década de 1990, o objeto de pesquisa da Retórica Contrastiva concentrou-se no processo de socialização dos gêneros acadêmicos e profissionais, e os modelos de escrita preferidos foram explorados em situações de uso da língua utilizada no contexto de fins específicos (CONNOR, 2001, p. 27).

Swales (1990, p. 58) define o gênero como um ato comunicativo que persegue uma finalidade concreta e que possui uma dimensão social reconhecível por uma dada comunidade linguística que compartilha os mesmos propósitos comunicativos. Assim, o uso da escrita por cada comunidade implica um discurso próprio que possui convenções concretas e que variam de acordo com as distintas comunidades discursivas profissionais e acadêmicas. Conclui-se daí que a habilidade de compor em uma língua não é extensível à habilidade de compor em outra que está sendo aprendida - e mesmo dentro da mesma língua, um texto profissional pode conter diferentes variáveis de organização na Espanha, Argentina e México -, devido ao fato de a escrita estar baseada em convenções culturais que devem ser adquiridas dentro da comunidade discursiva da língua específica que está sendo aprendida.

Essas diferenças podem não ser tão óbvias na forma como um parágrafo é escrito, mas estão na forma como a informação é organizada em um gênero, como intervêm elementos pragmáticos, como a cortesia, o grau de indiretividade, a finalidade da escrita ou o uso de fórmulas pré-estabelecidas, que terão sua contrapartida retórica na forma em que se estrutura o texto. Como alerta Kaplan (2000, XI), embora os estudantes sejam especialistas em um amplo inventário de gêneros em sua língua materna, espera-se que as 
características retóricas ou a própria finalidade dos gêneros não correspondam àquelas da língua estrangeira que estão aprendendo.

Talvez o maior avanço da Retórica Contrastiva nos últimos anos tenha sido alcançado com o auge da produção de textos escritos em língua estrangeira concernente ao meio acadêmico e às atividades profissionais, incidindo no estudo dos gêneros, até então distantes da sala de aula. Nestes estudos, são analisados tanto os aspectos relacionados ao processo de produção do texto quanto a forma de abordagem dos diferentes destinatários, a relação escritor-leitor, sua percepção das finalidades da escrita, os tipos de tarefa escrita, o contraste dos esquemas cognitivos. Por outro lado, os gêneros são dinâmicos e evoluem ao longo do tempo à medida que as práticas da sociedade mudam, pois os gêneros nada mais são do que textos sociais por meio dos quais se expressam as diferentes comunidades discursivas existentes em uma cultura. Portanto, pode-se afirmar que há uma adoção pessoal por parte do grupo social que acolhe uma nova realidade cultural. É por essa razão que o mesmo gênero muda de cultura para cultura e na mesma cultura ao longo do tempo. Isso é claramente observado em grande parte dos estudos de Retórica Contrastiva que abordam o gênero ${ }^{7}$ e que coincidem em ressaltar a transferência de modelos dos estilos retóricos da L1 para a L2, baseadas nas convenções escritas adquiridas em língua materna durante a escolarização.

Na década de 1990, padrões retóricos e outros padrões textuais micro e macro começaram a ser analisados. Como resultado dessa tradição, há uma tendência geral de comparar textos de gêneros semelhantes, ao contrário do que se fazia até então. Percebe-se então que não fazia sentido comparar textos argumentativos de estudantes de Direito com outros estudantes não universitários e até universitários de outras áreas, como Química, Física, História da Arte ou Arqueologia, para citar apenas alguns exemplos. Portanto, a partir desse período, colocou-se ênfase em controlar os experimentos e evitar esse tipo de comparação de grupos de informantes em condições desiguais (TRUJILLO SÁEZ, 2004, p. 67). Isso é afirmado, por exemplo, por Valero-Garcés (1996) em seu estudo que analisa padrões retóricos macro e microtextuais em textos da área de Economia escritos por falantes de espanhol e inglês. Em outra investigação exemplar dessa evolução da Retórica

\footnotetext{
${ }^{7}$ Para uma revisão abrangente desta questão, consultar Connor (1996).
} 
Contrastiva, Moreno (1997) estudou o metatexto causal na compreensão das relações de causa-efeito entre sentenças, observando artigos de pesquisa em Economia e Negócios em inglês e espanhol.

As pesquisas em Retórica Contrastiva, portanto, são enriquecidas com novos elementos - que incluem um fator fundamental, a percepção da audiência no texto e tudo o que isso acarreta (funções retóricas, cortesia, atenuação, persuasão etc.) - analisados com ferramentas interdisciplinares inovadoras que permitem aos autores explorar novos tópicos de estudo e metodologias inovadoras para incorporá-los em suas pesquisas.

\section{Novas críticas à Retórica Contrastiva e redefinição do termo "cultura"}

Novas críticas à Retórica Contrastiva surgiram no final dos anos 1990, quando em 1997 foram publicados os artigos de Spack (1997), Zamel (1997) e Scollon (1997), que têm como argumento comum a visão estreita que até então possuía o conceito de cultura para interpretar os estudos de Retórica Contrastiva. Dessa crítica, surgiu um novo construto teórico que tratou de redefinir o termo "cultura”, diferentemente da concepção geográfica ou da entidade nacional, até então entendidas como realidades imóveis e rigidamente homogêneas. Holliday (1994; 1999) é o primeiro a enunciar essa ideia a partir de uma perspectiva pós-moderna e a recobri-la sob o conceito "Small Cultures", em oposição à concepção clássica de grupo étnico ou nacional, recoberta pelo termo "Large Cultures". Assim, os estudos de Holliday recaem sobre os diferentes grupos sociais que constituem uma identidade por meio de características sociopolíticas que compartilham enquanto conjunto humano, por exemplo, a cultura nacional, mas também a da classe, a da disciplina, a da profissão etc.

Posteriormente, Atkinson (2003; 2004) recupera esse conceito e o relaciona com as práticas de composição na sala de aula de L2. Comenta como a reconceituação do termo cultura permite auxiliar e defender a Retórica Contrastiva das críticas recebidas desde a publicação do artigo de Kaplan (1966), em que a cultura fora compreendida a partir de uma perspectiva nacional que englobava diferentes grupos sociais e profissionais. Nas pesquisas realizadas em Retórica Contrastiva a partir da redefinição desse conceito, é possível delimitar ainda mais o objeto de estudo e definir com maior precisão o grupo sociolinguístico em estudo, de modo a definir suas 
características compartilhadas enquanto comunidade. Atkinson (2004) (Figura 2) apresenta seu modelo e discorre sobre sua aplicação sobre as habilidades de escrita em aulas de línguas.

\section{Figura 2 - Interação de "Small Cultures" na área educacional}

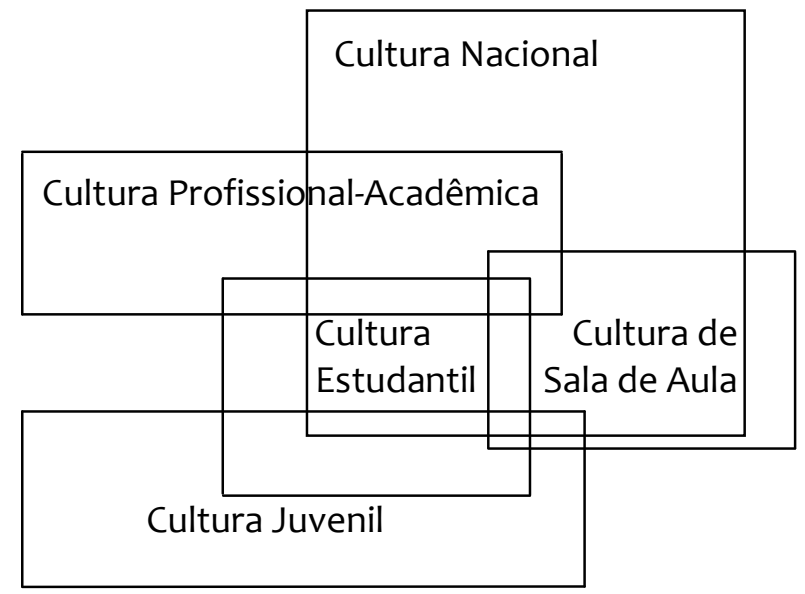

Fonte: Atkinson (2004, p. 285)

Como pode ser visto na Figura 2, não existe apenas uma cultura nacional, mas também outras culturas definidas por classe, idade, profissão ou grau de profissionalismo (especialista/amador), de modo que os pesquisadores que trabalham com este conceito ou o têm como objetivo devem considerar quais os tipos de "Small Cultures" estão implicados em seu estudo.

Trujillo Sáez (2005) concorda com essa abordagem do termo "cultura" e destaca a importância de defini-lo com precisão na pesquisa didática, porque "a definição conceitual determina nossa reflexão e nossa ação" (TRUJILLO SÁEZ, 2005, p. 23). Em seu artigo, além de fazer uma interessante revisão histórica desse termo, desde o início de seu estudo sistemático durante o Iluminismo até a pós-modernidade, Trujillo Sáez articula os termos "cultura" e “comunicação", já que ambos são de aplicação obrigatória no ensino de línguas. Connor (2008) $)^{8}$ é quem trata de forma conceitual dessa inter-relação

\footnotetext{
${ }^{8}$ Connor já insistia em artigo de 2001 que o fenômeno cultural da escrita não deveria ser explicado apenas pelas diferenças que advêm do contraste da nacionalidade dos grupos estudados, mas também da educação, das características de gênero ou das relações entre leitor e escritor etc., com as seguintes palavras: "Em vez disso, tentaram explicar as diferenças na comunicação escrita de várias fontes, incluindo L1, cultura nacional, treinamento educacional em L1, cultura disciplinar,
} 
pela primeira vez nos estudos de Retórica Contrastiva, justificando a mudança do nome da disciplina para ampliar seu escopo. Segundo Connor (2008, p. 313), o termo "retórica intercultural" refere-se não apenas aos estudos transculturais (base da Retórica Contrastiva), mas também aos interculturais.

Desde a primeira década do século XXI, o conceito de cultura entendido como "Small Cultures" ocupará um lugar central na pesquisa de Retórica Contrastiva. Quando o estudo transcultural e a comparação dos escritos da comunidade estavam mais em voga, por meio da análise dos gêneros discursivos nos quais se expressam, essa nova perspectiva é proposta na forma de compreender o conceito de cultura como resultado das interrelações de uma comunidade discursiva que compartilha peculiaridades bem definidas e as mesmas convenções escritas para transmitir suas comunicações (CONNOR, 2002, p. 503-504). Essa mudança implica que a abordagem da retórica não pode ser apenas linguística, como no início da Retórica Contrastiva, mas deve adotar uma perspectiva sociolinguística e cultural.

Portanto, nesta nova etapa, não é concebível realizar um estudo comparativo de dois grupos linguísticos diferentes sem levar em conta a comunidade discursiva a que pertencem. Deve-se primeiro estabelecer se os grupos são comparáveis com base na posição que ocupam na sociedade. Para isso, devem compartilhar o mesmo modelo cultural de escrita, ou seja, um gênero que tenha a mesma finalidade comunicativa, a mesma organização textual, seleção lexical etc. Esses estudos não só investigam a variação lexical, social, cognitiva e pragmática entre duas línguas, como também entre comunidades discursivas semelhantes dentro da mesma língua, tendo como objetivo identificar as dimensões de sua variação. Um bom exemplo dessa perspectiva é a Retórica Crítica, que estuda as relações entre grupos de poder e não-poder, especialmente as relações entre gêneros escritos produzidos por grupos discriminados em relação a outras comunidades sociais (TRUJILLO SÁEZ, 2004). Kubota e Lehner (2004) indicam como este é um campo muito fecundo (política, poder, pós-modernismo, pós-colonialismo, pedagogia crítica etc.), no qual a Retórica Contrastiva quase não fez nenhum esforço, parecendo ignorar deliberadamente a mudança de tendência iniciada por alguns pesquisadores que contribuíram para a publicação conjunta Contrastive

características de gênero e divergências nas expectativas mútuas entre os leitores e escritores" (CONNOR, 2001, p. 46). 
Rhetoric Revisited. No capítulo panorâmico escrito por Connor (2000, p. 78), a autora parabenizou as propostas feitas no livro (ideologia, raça, marginalização, exclusão etc.), porque permitiram a Retórica Contrastiva sair das aulas de língua estrangeira para ampliar seu horizonte. Da mesma forma, Corbett (2006) também se referiu à relevância que o estudo da expressão da ideologia em diferentes culturas adquire nesse livro. Em 2008, os mesmos tópicos voltam a aparecer em Contrastive Rhetoric: Reaching to Intercultural Rhetoric, publicação conjunta organizada por Connor, Nagehout e Rozychi (2008).

À semelhança do que sucedeu nas décadas anteriores, mais uma vez a crítica adversa à Retórica Contrastiva foi um auxílio que revitalizou a disciplina e permitiu a inclusão de mudanças inovadoras em campos como a cultura, o letramento e a pedagogia crítica. A Retórica Contrastiva, portanto, tem se mostrado uma disciplina dinâmica, que soube se alimentar das objeções levantadas em determinados momentos e soube se adequar às necessidades exigidas pela sociedade em cada período histórico.

\section{Novos desafios e rotas para Retórica Contrastiva}

Como comentado ao longo deste artigo, a Retórica Contrastiva ainda está em vigor em nossos dias, graças ao fato de ter sido capaz de se reinventar com eficácia a cada nova etapa e se adaptar com o tempo às novas correntes teóricas que surgiram na escrita, irmanando-se com outras disciplinas, quando necessário, que pudessem garantir sua sobrevivência e desenvolvimento. Esta disciplina soube evoluir e responder às novas necessidades que foram colocadas à sociedade no uso transcultural da escrita, com perspectivas renovadas para o futuro. Connor (1996; 2001; 2002; 2004; 2008; 2011), que tem contribuído ativamente para o desenvolvimento da disciplina, esteve presente com trabalhos fundamentais nas diferentes etapas da Retórica Contrastiva, que têm servido para apontar sucessivamente o novo roteiro a ser seguido pela disciplina nos anos posteriores.

Esta autora descreveu, em seus trabalhos mais recentes (CONNOR, 2001; 2002; 2008), os quatro possíveis caminhos pelos quais será necessário realizar um discurso contrastivo na retórica dos textos: o discurso feminista e o tratamento das minorias; a identificação diacrônica da evolução dos modelos de escrita (por exemplo, como as cartas de apresentação no ambiente de 
trabalho evoluíram nos últimos 50 anos); o estudo do contexto e da audiência aplicado aos novos meios de comunicação (páginas da web e tecnologias em diferentes culturas) e, por fim, Connor (2001; 2002) indicou a validade dos estudos empíricos nos modelos transculturais do texto e os diferentes comportamentos na escrita das diferentes comunidades discursivas nos campos acadêmico e profissional.

Sobre isso, Connor (2008, p. 299) fez um apelo à expansão da disciplina, recentemente rebatizada de Retórica Intercultural, a partir das três dimensões teóricas que permitirão o seu avanço no futuro:

- A escrita socialmente construída também deve considerar as práticas sociais, não apenas a escrita dos textos;

- A necessidade de dar atenção à pesquisa em "Small Cultures" para definir de uma maneira metodologicamente comparável a grupos sociais bem definidos;

- O estudo (etnográfico) da escrita como um encontro intercultural em que os escritores interagem na produção e compreensão de textos (etnografia).

Essas dimensões devem atuar em duas das constantes frentes que surgiram nos estudos de Retórica Contrastiva praticamente desde seu início: comtemplar os textos produzidos por escritores multilíngues e abordar os efeitos da persuasão na audiência (CONNOR, 2008, p. 299). Para isso, a Retórica Contrastiva deve também adaptar suas bases teóricas e metodológicas aos novos desafios que vão surgindo com o ritmo dos avanços da sociedade e das novas tecnologias. E, com a transformação da Retórica Contrastiva em Retórica Intercultural, confirma-se a vontade de continuar fazendo isso.

\section{Multiletramento}

Um dos princípios fundamentais da Retórica Contrastiva desde o seu início foi e é identificar as diferenças retóricas que ocorrem entre duas culturas, com o propósito pedagógico de ajudar os escritores de uma L2 na composição de seus escritos. É assim que o entendem dois dos principais mentores desta disciplina, que a defendem depois de trinta anos desde sua fundação: 
A verdade é que existem diferenças retóricas no discurso escrito em diferentes línguas, e estas devem ser levadas em consideração antes que o escritor possa começar a entender o que deve fazer para poder escrever de maneira semelhante a um nativo (ou de maneira aceitável aos falantes nativos da línguaalvo) [...]. Os estudantes devem estar cientes do fato de que a habilidade de escrever em uma língua não garante que eles tenham a mesma habilidade que os possibilita escrever em outra língua (GRABE; KAPLAN, 1996, p. 198).

Da mesma forma, Connor (2002, p. 505) marca uma postura que possibilita o ensino explícito das diferenças culturais de forma a produzir a desejável aculturação com a comunidade discursiva da L2, que é o objetivo final desta disciplina:

Alguns críticos da Retórica Contrastiva recentemente culparam-na por ensinar os alunos a escreverem usando as expectativas dos falantes nativos de inglês, em vez de expressar identidade linguística e cultural própria de sua língua materna. Os pesquisadores e outras partes interessadas, atualmente trabalhando no paradigma da Retórica Contrastiva, aderiram à posição de que as diferenças culturais devem ser explicitamente ensinadas a fim de aculturar os alunos de línguas estrangeiras à comunidade discursiva da língua que estão vivenciando a aprendizagem (CONNOR, 2002, p. 506).

Diante dessa perspectiva, outros autores têm criticado tal atitude e destacado a necessidade de que neste mundo globalizado e multilíngue as produções de escritores que elaboram seus textos em uma L2 sejam valorizadas, permitindo que se expressem de acordo com o estilo que rege sua própria idiossincrasia cultural em L1 (CANAGARAJAH, 2002; CASSANY, 2005a; 2005C; MORENO, 2010; MORENO et al 2012; FERGUSON; PÉREZLLANTADA; PLO, 2011; PÉREZ-LLANTADA; PLO; FERGUSON, 2011; PÉREZLLANTADA, 2012). Esses autores se opõem às recomendações didáticas dos acólitos da Retórica Contrastiva e à imposição a que se submetem os escritores que, seguindo as convenções retóricas do novo contexto da línguaalvo que estão aprendendo, elaboram seus textos em L2 despojados da própria identidade adquirida como escritores em sua $L 1$.

Essa é uma das possibilidades contempladas pelo multiletramento, uma nova tendência teórica que surge no campo dos estudos relacionados às novas tecnologias e à globalização, definida por Canagarajah (2003, p. 156) como uma nova forma de escrever e ler que engloba uma mistura de modalidades, sistemas simbólicos e linguagens:

O termo se refere às novas formas de ler e escrever que implicam uma mistura de modalidades, sistemas simbólicos e linguagens. Uma página da web típica, 
por exemplo, envolve a exibição de fotos, imagens em movimento (videoclipes) e gravações de áudio, bem como a escrita. Além do processamento desses diferentes modos de comunicação, os "leitores" também terão de interpretar diferentes sistemas de signos, como ícones e imagens, além de palavras. Além disso, textos em línguas tão diversas como o francês e o árabe podem ser reunidas em um site em inglês. Diferentes discursos podem ser encontrados juntos, como jurídicos, terminologia médica e descrições estatísticas, além da linguagem conversacional que usamos no discurso oral cotidiano (CANAGARAJAH, 2003, p. 156).

Os estudos do multiletramento contemplam tanto a integração de várias linguagens, registros ou gêneros em um mesmo discurso como o comportamento do escritor-leitor que se depara com uma alternância de linguagens, registros ou gêneros em um curto espaço de tempo na tela de seu computador. Como resultado desse processo de análise, escritores multilíngues podem adotar, segundo Canagarajah (2003, p. 156), cinco estratégias de acordo com a forma como cada escritor aborda o discurso em L2 com uma retórica diferente, confrontando-a com as convenções culturais que ele possui em sua língua materna:

1. Acomodação 9 : é a perspectiva adotada pela Retórica Contrastiva, pela qual o escritor deve renunciar às convenções retóricas adquiridas em sua L1 para adotar as novas em L2;

2. Evitação: é a mais típica entre os escritores que possuem menos recursos linguísticos e se caracteriza pela aceitação das convenções discursivas estabelecidas em L2. Embora siga a mesma filosofia da acomodação, devido à competência linguística inadequada, textos incoerentes são produzidos e ele incorpora involuntariamente traços da retórica de sua língua materna;

3. Oposição: os traços retóricos da língua materna são incorporados de forma voluntária e predeterminada, amalgamando-se com os da L2;

4. Transposição: por meio dessa estratégia, um novo espaço textual é criado a partir da mistura das retóricas da L1 e da L2, tecidas de modo que o produto resultante tenha uma nova forma discursiva que não responda nem às convenções da L1 nem da L2;

5. Apropriação: incorpora as convenções discursivas da língua materna, ainda que a retórica dominante seja a da L2. Embora seja semelhante à

\footnotetext{
${ }^{9}$ Tanto na tradução quanto na definição dos termos, seguimos Cassany (2005b).
} 
transposição, a maior diferença está na proporcionalidade, ou seja, na apropriação se reconhece a estrutura dominante da L2 frente à paridade de L1 e L2 para construir um terceiro discurso, como é o caso da transposição.

Os estudos do multiletramento propõem uma perspectiva interessante na medida em que incentiva uma negociação retórica a partir do contexto de uso em que o escritor se encontra, podendo preservar as características da escrita de cada uma das línguas que conhece e enriquecer a escrita com a contribuição de retórica estrangeira, afastando-se da rigidez regulatória imposta pela Retórica Contrastiva a esse respeito.

Não há necessidade de comentar o efeito que a globalização está tendo nos estilos e gêneros da escrita, razão pela qual os textos contaminados com elementos anglófonos são cada vez mais abundantes e é cada vez mais frequente encontrar formas de escrita cada vez mais homogêneas em todo o mundo, das quais os gêneros também são permeados. Connor (2001; 2002) fala, neste sentido, da Euroretórica como uma nova forma de linguagem escrita em que se fundiriam as normas das diferentes orientações retóricas de todos aqueles escritores que se expressam em inglês, mas que têm uma L1 diferente, em consonância com o World Standard Spoken English (inglês global ou inglês internacional) descrito por Crystal (1997), no qual indivíduos de países não anglófonos se comunicam. A consequência dessa padronização é que, gradualmente, as características idiossincráticas das culturas irão perdendo, especialmente nos setores em que as relações internacionais são frequentemente estabelecidas, como o mundo empresarial ou acadêmico. Um exemplo desse fenômeno é ilustrado por Salager-Meyer, Alcaraz Ariza e Zambrano (2003) em uma pesquisa em que analisaram diacronicamente 90 textos médicos.

Com base nos seus dados, as autoras Salager-Meyer, Alcaraz Ariza e Zambrano (2003, p. 242) se perguntaram por quanto tempo mais os países não anglófonos conseguiriam suportar a padronização e a globalização da língua exercida pela influência do inglês, especialmente no campo científico. A pesquisa mostrava como a retórica dos artigos médicos escritos em inglês, espanhol e francês no período entre 1930 e 1995 havia se aproximado por terem adotado as convenções retóricas do inglês. 
Por essa razão, é bastante provável que, se estudos como os discutidos anteriormente por Hinds (1983; 1987; 1990), Purves (1988) ou Liebman (1992) fossem replicados, estes produziriam dados semelhantes compartilhados entre si. Algo semelhante foi observado nos últimos anos no contexto da retórica asiática. Padrões retóricos ocidentais foram incorporados a essas culturas que progressivamente suavizaram as características idiossincráticas tradicionalmente atribuídas à retórica asiática. E isso acontece por que as convenções retóricas vieram homogeneizando-se ao longo dos anos e pelos efeitos da globalização, da aprendizagem generalizada de línguas nas instituições de ensino, da troca diária de informações que fluem pela mídia, do mundo do trabalho sustentado pelas novas tecnologias.

Mais de cinquenta anos depois do artigo seminal de Kaplan (1966) e após décadas de refundação e constante reavaliação da disciplina, a Retórica Contrastiva, transformada em Retórica Intercultural, tem de se reinventar novamente para enfrentar esses novos desafios impostos pela sociedade globalizada da informação e da tecnologia, caracterizada pela homogeneização da diversidade e pela mudança acelerada e contínua. As respostas, como no passado, servirão para facilitar a comunicação e o entendimento entre os seres humanos.

\section{Referências}

AINCIBURU, María Cecilia. Recursos para estudiar el español académico a partir de corpus. Revista Nebrija de Lingüística Aplicada, n. 12, 2012.

ATKINSON, Dwight. Contrasting rhetorics/contrasting cultures: Why contrasting rhetoric needs a better conceptualization of culture. Journal of English for Academic Purposes, v. 3, n. 4, p. 277-289, 2004.

ATKINSON, Dwight. Writing and culture in the post-process era. Journal of Second Language Writing, n. 12, p. 49-63, 2003.

BLOOMFIELD, Leonard. Language. Chicago: University of Chicago Press, 1933.

CANAGARAJAH, Suresh. Multilingual Writers and the Academic Community: Towards a Critical Relationship. Journal of English for Academic Purposes, v.1, n. 1, p. 29-44, 2002. 
CANAGARAJAH, Suresh. Practicing multiliteracies. Journal of Second Language Writing, n. 12, p. 156-165, 2003.

CASSANY, Daniel. Investigaciones y propuestas sobre literacidad actual: multiliteracidad, internet y criticidad. CONGRESO NACIONAL CÁTEDRA UNESCO PARA LA LECTURA Y LA ESCRITURA, 1, 2005, Concepción, Chile, Conferencia [...]. Concepción: Universidad de Concepción, 2005a.

CASSANY, Daniel. Expresión escrita en L2/ELE. Madrid: Arco Libros, 2005b.

CASSANY, Daniel. Investigaciones sobre la lectura y escritura multilingües desde las ciencias del lenguaje. In: Esmeralda Matute (ed.). Aprender a leer y escribir en diferentes lenguas y realidades. Guadalajara: Universidad de Guadalajara, 2005c.

CHRISTENSEN, Francis. A generative rhetoric of the sentence. College Composition and Communication, v. 14, n. 3, p. 155-161, 1963.

CONNOR, Ulla. Changing Currents in Contrastive Rhetoric: New Paradigms. In: MORENO, Ana I.; COLWELL, Vera (eds.). Perspectivas recientes sobre el Discurso. León: Universidad de León, 2001. p. 27-56.

CONNOR, Ulla. Intercultural rhetoric research: Beyond texts. Journal of English for Academic Purposes, v. 3, n. 4, p. 291-304, 2004.

CONNOR, Ulla. Mapping multidimensional aspects of research: Reaching to intercultural rhetoric. In: CONNOR, Ulla; NAGELHOUT, Ed; ROZYCKI, William (eds.). Contrastive rhetoric: Reaching to intercultural rhetoric. Amsterdam: John Benjamins, 2008. p. 299-315.

CONNOR, Ulla. New Directions in contrastive rhetoric. TESOL Quarterly, v. 36, n. 4, p. 493-510, 2002.

CONNOR, Ulla. Contrastive Rhetoric. Cross-cultural aspects of second language writing. Cambridge: Cambridge University Press, 1996.

CONNOR, Ulla. Intercultural rhetoric in the writing classroom. Ann Arbor: The University of Michigan Press, 2011.

CONNOR, Ulla; NAGELHOUT, Ed; ROZYCKI, William (eds.). Contrastive rhetoric: Reaching to intercultural rhetoric. Amsterdam: John Benjamins, 2008.

CORBETT, John. Genre and genre analysis. In: MEY, Jacob L. (ed.). Concise Encyclopedia of Pragmatics. Oxford: Elsevier, 2006. p. 286-292.

CRYSTAL, David. English as a global language. Cambridge: Cambridge University Press, 1997. 
FERGUSON, Gibson; PÉREZ-LLANTADA, Carmen; PLO, Ramón. English as an International Language of Scientific Publication: A Study of Attitudes. World Englishes - Journal of English as an International and Intranational Language, v. 30, n. 1, p. 41-59, 2011.

GRABE, William; KAPLAN, Robert B. Theory and Practice of Writing. London: Longman, 1996.

HINDS, John. Linguistics and written discourse in particular languages: contrastive studies: English and Japanese. Annual review of applied linguistics, v. 3, p. 78-84, 1983.

HINDS, John. Reader versus Writer Responsibility: A New Typology. In: CONNOR, Ulla; KAPLAN, Robert B. (ed.). Writing Across Languages: Analysis of L2 Text. Reading, Massachusetts: Addison-Wesley, 1987. p. 141-152.

HINDS, John. Inductive, deductive, quasi-inductive: Expository writing in Japanese, Korean, Chinese, and Thai. In: CONNOR, Ulla; JOHNS, Ann. E. (eds.). Coherence in writing: Research and pedagogical perspectives. Alexandria: Teachers of English to Speakers of Other Languages, 1990. p. 87-109.

HOLLIDAY, Adrian. Appropriate methodology and social content. Cambridge: Cambridge University Press, 1994.

HOLLIDAY, Adrian. Small cultures. Applied Linguistics, v. 20, n. 2, p. 237-264, 1999.

INDRASUTA, Chantanee. Narrative styles in the writing of Thai and American students. In: PURVES, Alan C. (ed.). Writing across languages and cultures: Issues in contrastive rhetoric. Newbury Park: Sage, 1988. p. 206-227.

KAPLAN, Robert B. Cultural Thought Patterns in Inter-cultural Education. Language Learning, n. 16, p. 1-20, 1966.

KAPLAN, Robert B. Contrastive rhetoric: some hypotheses. ITL - International Journal of Applied Linguistics, v. 39-40, p. 61-72, 1978.

KAPLAN, Robert B. Contrastive rhetorics: Some implications for the writing process. In: FREEDMAN, Aviva; PRINGLE, lan; Yalden, Janice (eds.). Learning to write: First language/Second language. London: Longman, 1983.

KAPLAN, Robert B. Cultural Thought Patterns Revisted. In: CONNOR, Ulla; KAPLAN, Robert B. (eds). Writing Across Languages: Analysis of L2 Text. Massachusetts: Addison-Wesley, 1987. p. 9-22.

KAPLAN, Robert B. Contrastive Rhetoric and Second Language Learning: Notes Toward a Theory of Contrastive Rhetoric. In: PURVES, Alan C. (ed.). Writing Across Languages and Cultures: Issues in Contrastive Rhetoric. Newbury Park: Sage Publications, 1988. p. 275-304. 
KAPLAN, Robert B. Foreword: What in the world is contrastive rhetoric?" In: PANETTA, Clayann (ed.). Contrastive rhetoric revisited and redefined. New York: Lawrence Erlbaum Associates, 2000. p. VII-XX.

KROLL, Barbara. Introduction: Teaching the next generation of second language writers. In: KROLL, Barbara (ed.). Exploring the dynamics of second language writing. New York: CUP, 2003. p. 1-14.

KUBOTA, Ryuko. An investigation of L1-L2 transfer in writing among Japanese university students: Implications for contrastive rhetoric. Journal of Second Language Writing, v. 7, p. 69-100, 1998.

KUBOTA, Ryuko. Word processing and WWW projects in a college Japanese language class. Foreign Language Annals, v. 32, n. 2, p. 205-218, 1999.

KUBOTA, Ryuko; LEHNER, Al. Toward critical contrastive rhetoric. Journal of Second Language Writing, v. 13, n. 1, p. 7-27, 2004.

LEKI, Ilona. Twenty-Five Years of Contrastive Rhetoric: Text Analysis and Writing Pedagogies. TESOL Quarterly, v. 25, n. 1, p. 123-143, 1991.

LIEBMAN, Joanne. Toward a new contrastive rhetoric: differences between Arabic and Japanese rhetorical instruction. Journal of Second Language Writing, v. 1, n. 2, p. 141-165, 1992.

MATALENE, Carolyn. Contrastive Rhetoric: An American Writing Teacher in China. College English, v. 47, n. 8, p. 789-808, 1985.

MATSUDA, Paul K. Contrastive rhetoric in context: A dynamic model of L2 writing. Journal of Second Language Writing, v. 6, n. 1: p. 45-60, 1977.

MATSUDA, Paul K. Second language writing in the twentieth century: A situated historical perspective. In: KROLL, Barbara (ed.). Exploring the dynamics of second language writing. New York: Cambridge University Press, 2003. p. 15-34.

MOHAN, Bernard A.; LO, Winnie. Academic writing and Chinese students: Transfer and developmental factors. TESOL Quarterly, v. 19, n. 4, p. 513-534, 1985.

MONTAÑO-HARMON, María R. Discourse features of written Mexican Spanish: current research in contrastive rhetoric and its implications. Hispania, v. 74, p. 417425, 1991.

MORENO, Ana I. Genre constraints across languages: causal metatext in Spanish and English RAs. English for Specific Purposes, v. 16, n. 3, p. 161-179, 1997. 
MORENO, Ana I. Researching into English for research publication purposes from an applied intercultural perspective. In: RUIZ-GARRIDO, Miguel F.; PALMER-SILVEIRA, Juan C.; FORTANET-GÓMEZ, Inmaculada (eds). English for Professional and Academic Purposes. Amsterdam: Rodopi, 2010. p. 57-71.

MORENO, Ana I.; REY-ROCHA, Jesús; BURGESS, Sally; LÓPEZ-NAVARRO, Irene; ITESH, Sachdev. Spanish researchers' perceived difficulty writing research articles for English medium journals: the impact of proficiency in English versus publication experience. Ibérica, v. 24, p. 157-184, 2012.

PALTRIDGE, Brian. Discourse Analysis. 2.ed. London: Continuum, 2012.

PANETTA, Clayann (ed.). Contrastive rhetoric revisited and redefined. New York: Lawrence Erlbaum Associates, 2000.

PASTOR VILLALBA, Carmen. Estudio transcultural del texto argumentativo: la carta de queja en español y en alemán. Universidad Antonio de Nebrija: Madrid, 2005.

PÉREZ-LLANTADA, Carmen. Scientific Discourse and the Rhetoric of Globalization. The Impact of Culture and Language. London, New York: Continuum, 2012.

PEREZ-LLANTADA, Carmen; PLO, Ramón; FERGUSON, Gibson. You don't say what you know, only what you can: The Perceptions and Practices of Senior Spanish Academics regarding Research Dissemination in English. English for Specific Purposes Journal, v. 30, n. 1, p. 18-30, 2011.

PINKER, Steven. The language instinct. New York: Morrow. Pitman, RK, 1994.

PURVES, Alan.C. Writing Across Languages and Cultures: Issues in Contrastive Rhetoric. Newbury Park: Sage Publications, 1988.

PURVES, Alan.C. (ed.). The IEA study of written composition II: Education and performance in 14 countries. Oxford: Pergamon Press, 1992.

PURVES, Alan C.; PURVES, William. Viewpoints: Cultures, Text Models, and the Activity of Writing. Research in the Teaching of English, v. 20, n. 2, p. 174-197, 1986.

RAIMES, Ann. Out of the woods: Emerging traditions in the teaching of writing. TESOL Quarterly, v. 25, p. 407-430, 1991.

RAMANATHAN, Vaidehi; KAPLAN, Robert B. Response to Raimes and Zamel. Journal of Second Language Writing, v. 6, p. p. 83-88, 1997.

SALAGER-MEYER, Françoise, ALCARAZ ARIZA, María Ángeles; ZAMBRANO, Nahirana. The scimitar, the dagger and the glove: intercultural differences in the rhetoric of criticism in Spanish, French and English Medical Discourse (1930-1995). English for Specific Purposes, v. 22, n. 3, p. 223-247, 2003. 
SANTANA-SEDA, Olga. An analysis and contrast in the organization of paragraphs written by university students. Tese (Doutorado). New York: New York University, 1974.

SCOLLON, Ron. Contrastive rhetoric, contrastive poetics, or perhaps something else? TESOL Quarterly, v. 31, p. 352-363, 1997.

SÖTER, Anna. The Second Language Learner and Cultural Transfer in Narration. In: PURVES, Alan C. (ed.). Writing Across Languages and Cultures: issues in Contrastive Rhetoric. New York: Sage Publications, 1988.

SPACK, Ruth. The rhetorical construction of multilingual students. TESOL Quarterly, v. 31, p. 765-774, 1997.

SWALES, John. Genre analysis: English in academic and research settings. Cambridge. England and New York: Cambridge University Press, 1990.

TARONE, Elaine. On the variability of interlanguage systems. Applied Linguistics, v. 4, n. 2, p. 142-163, 1983.

TRUJILLO SÁEZ, Fernando. Implicaciones didácticas de la Retórica Contrastiva para la enseñanza de la lengua. Lenguaje y Textos, v. 17, p. 79-90, 2001.

TRUJILLO SÁEZ, Fernando. Retórica Contrastiva y expresión escrita. Evaluación y estudio de textos en inglés y en español. Tese (Doutorado em Educação) - Facultad de Educación y Humanidades de Ceuta, Universidad de Granada, 2002.

TRUJILLO SÁEZ, Fernando. Investigación en Retórica Contrastiva: Escritura y Cultura en conexión. Conferência proferida na Universidade de Milão. 2004. Disponível em: http://www.ledonline.it/mpw/allegati/mpw0403trujillo.pdf.

TRUJILLO SÁEZ, Fernando. En torno a la interculturalidad: reflexiones sobre cultura y comunicación para la didáctica de la lengua. Porta Linguarum: revista internacional de didáctica de las lenguas extranjeras, n. 4, p. 23-39, 2005.

VALERO-GARCÉS, Carmen. Contrastive ESP Rhetoric: Metatext in Spanish-English Economic Texts. English for Economic Purposes, v. 15, n. 4, p. 279-294, 1996.

VEZ JEREMÍAS, José Manuel. De la lingüística del contraste a la didáctica de la integración en las aulas de lengua extranjera. Un punto de vista crítico. Carabela, v. 51, p. 5-25, 2002.

XING, Minjie; WANG, Jinghui; SPENCER, Kenneth. Raising Students'awareness of cross-cultural contrastive rhetoric in English writing via an e-learning course. Language Learning \& Technology, v. 12, n. 2, p. 71-93, 2008.

ZAMEL, Vivian. Toward a model of transculturation. TESOL Quarterly, v. 31, p. 341343, 1997. 
Forma de citação sugerida conforme ABNT

SÁNCHEZ-JIMÉNEZ, David. 50 anos de evolução nos estudos linguísticos transculturais: da Retórica Contrastiva à Retórica intercultural. Tradução: Mirélia Ramos Bastos Marcelino, Cristiano Costa Magalhães e Eduardo Lopes Piris. EID\&A Revista Eletrônica de Estudos Integrados em Discurso e Argumentação, Ilhéus, n. 20, v. 2, p. 165-199, ago. 2020. http://dx.doi.org/10.47369/eidea-20-2-2798. 